\title{
Species composition, seasonal changes and community ordination of alkalotolerant micro fungal diversity in a natural scrub jungle ecosystem of Tamil Nadu, India
}

\author{
Muthukrishnan $\mathrm{S}^{*}$, Sanjayan KP and Jahir HK \# \\ G.S. Gill Research Institute, Guru Nanak College, Velachery, Chennai -600 042, India. \\ ${ }^{\circledR}$ Present address: Sun Agro Biotech Research Centre, Porur, Chennai - 600 116, India. \\ \#Present address: Environment and Safety Division, Indira Gandhi Centre for Atomic Research, Kalpakkam- 603 102, \\ India.
}

Muthukrishnan S, Sanjayan KP, Jahir HK 2012 - Species composition, seasonal changes and community ordination of alkalotolerant micro fungal diversity in a natural scrub jungle ecosystem of Tamil Nadu, India. Mycosphere 3(2), 92-109, Doi 10.5943/mycosphere/3/2/1

One hundred and seven species of alkalotolerant fungi were isolated from different layers of litter of the Guindy Reserve Forest, Chennai, South India during a 2-year period. They comprised Zygomycota (7 species), Ascomycetes (4 species), hyphomycetes ( 86 species) and coelomycetes (10 species). The F1 litter layer, just beneath the recently fallen leaves, had the richest composition of fungi and the fungi were most abundant during the North East monsoons (September to November). Shannon's diversity index and Simpson diversity index $\lambda$ indicate F1 layer to have the maximum species. The species distribution fell into the log series model and Fishers alpha was also highest for the F1 layer. Species richness indices computed also indicated that none of the species was more predominant. Values of species evenness computed hovered around 0.6 indicating a tilt towards even distribution of the species. The fungal community is a heterogenous assembly of species derived from a homogenous habitat with a log normal pattern of distribution formed due to the interplay of many independent factors governing the relative abundance of the species. Principal component ordination analysis reveals that the greatest variation in the species composition was due to the South West monsoon. Also, detrended correspondence data put the species abundance data for the four seasons in a linear arrangement.

Key wards - Alkalotolerant fungi - Fungal diversity - Micro fungi - Plant Litter

Article Information

Received 3 February 2012

Accepted 6 February 2012

Published online 3 March 2012

*Corresponding author: Muthukrishnan S - e-mail - krish_522@yahoo.com

\section{Introduction}

One third of fungal diversity of the globe exists in India. Fungi play a significant role in the daily life of human beings besides their utilization in industry, agriculture, medicine, food industry, textiles, bioremediation, natural cycling, as biofertilizers and many other ways (Manohara-chary et al. 2005). Fungi play an important role in plant litter decomposition in forest ecosystems through nutrient recycling and humus formation in soil (Swift et al. 1979) because they attack the lignocellulose matrix in litter that other organisms are unable to assimilate (Kjoller \& Struwe 1982, Cooke \& Rayner 1984). Alkalineadapted micro-organisms can be classified into two main groupings, alkaliphiles (also called alkalophiles) and alkalitolerants or alkalotolerant. The term alkaliphiles is generally restricted to those micro-organisms that actually require alkaline media for growth. The optimum growth rate of these micro-organisms 
is observed in at least two $\mathrm{pH}$ units above neutrality. Organisms capable of growing at $\mathrm{pH}$ values more than 9 or 10 , but with optimum growth rates at around neutrality or less, are referred to as alkalotolerant (Jones et al. 1994). Exploration of natural, alkalotolerant fungi for the production of industrially important alkaline active cellulose, protease, amylase, lipase, and mannose is gaining momentum. It is increasingly realized that fungi may be good sources of new compounds, beneficial to mankind. For example, in modern detergents there is a need for enzymes that actively work in alkaline conditions (Horikoshi 1999). Alkaline active enzymes are used to decompose the gelatin on film, degradation of paper in paper industry and in detergent additives. Alkaline enzymes have been also used in the hide-dehairing process. Given these extensive commercial application there is a need to build a germplasm collection of alkalotolerant fungi. The focus of this study is to enumerate the species diversity of alkalotolerant fungi inhabiting the different layers of the litter of a natural scrub jungle ecosystem and also to record the seasonal changes in species composition.

\section{Materials and methods}

Litter samples were collected from the Guindy Reserve Forest (GRF) is a $2.82 \mathrm{~km}^{2}$ protected area of Tamil Nadu, located in Chennai, South India located at $13^{\circ} 0^{\prime} 20^{\prime \prime} \mathrm{N}$ and $80^{\circ} 13^{\prime} 24^{\prime \prime}$ E. It is a dry evergreen scrub and thorn forest with over 350 species of plants including shrubs, climbers, herbs and grasses and over 24 varieties of trees, growth of colonies at alkaline $\mathrm{pH}$ in the laboratory.

Samples were taken from three layers of the litter namely: 1) L-layer which is the uppermost layer consisting of recently fallen senescent leaves lying loosely on the surface. The structure of the leaves is well preserved and they are yellowish to light brown in colour, dry and without any visible fungal growth; 2) F1layer which occurs immediately below the $\mathrm{L}$ layer, has high moisture content and consists of dark brown leaves, usually compacted. The leaf structure is reasonably well preserved but slightly thinner and soft. The leaves show patches of visible fungal growth suggesting that they are under active decomposition; and 3) F2- layer which is the lowermost layer lying between F1 layer and the soil surface below. The leaves are in advanced stages of decomposition, usually fragmentary, very thin and tightly compressed.

Litter samples were collected each month for 3 years. Each layer of litter samples were collected separately from different locations of GRF in sterile polythene zip cover for fungal analysis and the data was grouped to represent four seasons: i) South West monsoon (June-August); ii) North East monsoon (September-November); iii) Post monsoon period (December-February); and iv) Summer (MarchMay). The leaf samples were randomly selected from sealed polythene zip cover and cut into pieces approximately $1 \mathrm{~cm}^{2}$ with a pair of sterile scissors and washed in $100 \mathrm{ml}$ of sterile water in a $250 \mathrm{ml}$ Ehrlenmeyer flask. The flask was placed on a shaker for 30 minutes. From this initial suspension, serial dilutions were prepared. One $\mathrm{ml}$ of the required dilution $(1 / 1000)$ was pipetted on the surface of already prepared replicate plates containing potato dextrose agar with antibiotic Streptomycin sulphate $(300 \mu \mathrm{g} / \mathrm{ml})$. The medium was maintained to $\mathrm{pH} 8$ using sodium carbonate (Horikoshi \& Akiba 1982). The plates were incubated at room temperature in glass chambers under aseptic conditions for 4 days and then examined for fungal growth. All fungal colonies that developed were recorded, isolated and identified. The periodicity of occurrence of each species of fungus was calculated based on the number of samples in which they occurred against the total number of samples collected and the species were classified into four groups: 'most common' (76100\%), 'common'(51-75\%), 'occasional' (26$50 \%)$ and 'sporadic' (1-25\%).

The following diversity indices were calculated as a measure of $\alpha$-diversity - Fisher's $\alpha$, Shannon's diversity index $\left(\mathrm{H}^{\prime}\right)$, Simpson's diversity index $(\lambda)$, Margalef's richness index (R1), Menhinick's richness index (R2), and Evenness indices (E1, E2, E3, E4 and E5) using the software of Paleontological Statistics (PAST) Version 1.92. The Morisita-Horn index was calculated as a measure of between habitat diversity ( $\beta$ - diversity). 
Table 1 List of fungal species isolated from three layers of litter of the Guindy Reserve forest and their periodicity of occurrence.

\begin{tabular}{|c|c|c|c|c|}
\hline S.No & Fungal Species & L-LAYER & F1-LAYER & F2-LAYER \\
\hline & ZYGOMYCOTINA & & & \\
\hline 1 & Absidia corymbifera & Occasional & Occasional & Occasional \\
\hline 2 & Cunninghamella echinulata & Sporadic & Occasional & Sporadic \\
\hline 3 & C. elegans & & Sporadic & \\
\hline 4 & Helicostylum piriforme & & Sporadic & \\
\hline 5 & Mucor racemosus & Common & Most common & Common \\
\hline 6 & Rhizopus stolonifer & Common & Common & Common \\
\hline \multirow[t]{2}{*}{7} & Syncephalastrum racemosum & Occasional & Occasional & Occasional \\
\hline & ASCOMYCOTINA & & & \\
\hline 8 & Anthostoma simplex & & Sporadic & \\
\hline 9 & Ascotricha chartarum & Sporadic & Sporadic & \\
\hline 10 & Chaetomium longirostre & & Sporadic & Sporadic \\
\hline \multirow[t]{2}{*}{11} & C.globosum & Sporadic & Sporadic & Sporadic \\
\hline & \multicolumn{2}{|c|}{ DEUTEROMYCOTINA: HYPHOMYCETES } & & \\
\hline 12 & Acremonium strictum & Sporadic & Occasional & Sporadic \\
\hline 13 & Alternaria alternata & Occasional & Common & Occasional \\
\hline 14 & A. longipes & Occasional & Sporadic & \\
\hline 15 & Aspergillus candidus & Sporadic & Sporadic & Sporadic \\
\hline 16 & A. flavipes & & & Sporadic \\
\hline 17 & A. flavus & Most common & Most common & Occasional \\
\hline 18 & A. fumigatus & Common & Most common & Most common \\
\hline 19 & A. japonicus & Common & Common & Occasional \\
\hline 20 & A. nidulans & Occasional & Occasional & Sporadic \\
\hline 21 & A. niger & Most Common & Most Common & Most common \\
\hline 22 & A. ochraceus & Occasional & Most common & Occasional \\
\hline 23 & A. sydowii & & & Sporadic \\
\hline 24 & A. tamarii & Sporadic & & Sporadic \\
\hline 25 & A. terreus & Occasional & Occasional & Occasional \\
\hline 26 & A. versicolor & Occasional & Occasional & Sporadic \\
\hline 27 & Aureobasidium pullulans & Sporadic & Sporadic & \\
\hline 28 & Beltrania mangiferae & & Sporadic & \\
\hline 29 & B. rhombica & & & Sporadic \\
\hline 30 & Beltraniella portoricensis & & Sporadic & \\
\hline 31 & Beltraniopsis asperisetifer & & Sporadic & \\
\hline 32 & Ceratosporium fuscescens & & Sporadic & \\
\hline 33 & Chrysosporium pannorum & Sporadic & & \\
\hline 34 & Chaetochalara africana & & Sporadic & Sporadic \\
\hline 35 & Circinotrichum fertile & & Sporadic & \\
\hline 36 & Cladosporium cladosporioides & Sporadic & Sporadic & Occasional \\
\hline 37 & C. oxysporum & Occasional & Common & Occasional \\
\hline 38 & Curvularia lunata & Occasional & Common & Occasional \\
\hline 39 & C. brachyspora & Sporadic & Sporadic & Sporadic \\
\hline 40 & C. eragrostidis & Occasional & Occasional & Occasional \\
\hline 41 & C. oryzae & Occasional & & \\
\hline 42 & C. pallescens & Occasional & & \\
\hline 43 & C. tuberculata & Sporadic & & Sporadic \\
\hline 44 & Cordana vasiformis & & Occasional & \\
\hline 45 & Dendryphion comosum & & Sporadic & \\
\hline 46 & Dictyosporium heptasporum & & Sporadic & \\
\hline 47 & Drechslera australiensis & Sporadic & Occasional & Sporadic \\
\hline 48 & D. halodes & Sporadic & Sporadic & Sporadic \\
\hline 49 & D. hawaiiensis & Sporadic & Occasional & Sporadic \\
\hline 50 & D. rostrata & & Occasional & \\
\hline 51 & Fusarium moniliforme & Sporadic & & \\
\hline
\end{tabular}


Mycosphere Doi 10.5943/mycosphere/3/2/1

\begin{tabular}{|c|c|c|c|c|}
\hline S.No & Fungal Species & L-LAYER & F1-LAYER & F2-LAYER \\
\hline 52 & F. oxysporum & Occasional & Common & Occasional \\
\hline 53 & F. solani & & Sporadic & \\
\hline 54 & Geotrichum candidum & Sporadic & & \\
\hline 55 & Gliocladium roseum & & Sporadic & Sporadic \\
\hline 56 & Gliomastix murorum & & Sporadic & \\
\hline 57 & Humicola grisea & & Sporadic & Sporadic \\
\hline 58 & Henicospora coronate & & Sporadic & \\
\hline 59 & Memnoniella echinata & Sporadic & Sporadic & \\
\hline 60 & Monilia sitophila & Sporadic & & Sporadic \\
\hline 61 & Monodictys glauca & Sporadic & Sporadic & Sporadic \\
\hline 62 & M. levis & occasional & Sporadic & \\
\hline 63 & Myrothecium indicum & & Sporadic & \\
\hline 64 & M. gramineum & & Sporadic & \\
\hline 65 & M. roridum & Sporadic & Sporadic & \\
\hline 66 & M. verrucaria & Sporadic & Sporadic & Sporadic \\
\hline 67 & Nigrospora sphaerica & Sporadic & Sporadic & Sporadic \\
\hline 68 & Paecilomyces carneus & Sporadic & Occasional & Sporadic \\
\hline 69 & P. variotii & Sporadic & Sporadic & \\
\hline 70 & Periconia clitoriae & Sporadic & & \\
\hline 71 & Penicillium citrinum & Most common & Most common & Common \\
\hline 72 & P. chrysogenum & Sporadic & & Sporadic \\
\hline 73 & P. fellutanum & Sporadic & Sporadic & Sporadic \\
\hline 74 & P. frequentans & Sporadic & & Sporadic \\
\hline 75 & P. funiculosum & Sporadic & & Sporadic \\
\hline 76 & P. islandicum & Sporadic & & \\
\hline 77 & P. oxalicum & Sporadic & & Occasional \\
\hline 78 & P. purpurescens & Sporadic & Occasional & \\
\hline 79 & P. purpurogenum & Sporadic & Sporadic & \\
\hline 80 & Pithomyces chartarum & & Sporadic & \\
\hline 81 & P. maydicus & Sporadic & Sporadic & \\
\hline 82 & Selenosporella curvispora & & Sporadic & \\
\hline 83 & Scolecobasidium constrictum & Sporadic & Occasional & Sporadic \\
\hline 84 & S. humicola & & Sporadic & \\
\hline 85 & Scopulariopsis brevicaulis & Sporadic & Sporadic & \\
\hline 86 & Sporothrix sp. & & Sporadic & \\
\hline 87 & Stachybotrys atra & Sporadic & Sporadic & Sporadic \\
\hline 88 & S. bisbyi & Sporadic & Sporadic & Sporadic \\
\hline 89 & Thielaviopsis basicola & & Sporadic & \\
\hline 90 & T. paradoxa & & Sporadic & Sporadic \\
\hline 91 & Trichoderma atroviride & & & Sporadic \\
\hline 92 & T. harzianum & Occasional & Occasional & Occasional \\
\hline 93 & T. koningii & Sporadic & Sporadic & \\
\hline 94 & T. polysporum & & Sporadic & \\
\hline 95 & T. pseudokoningii & & Sporadic & \\
\hline 96 & T. roseum & & Sporadic & Sporadic \\
\hline 97 & T. viride & Occasional & Occasional & Sporadic \\
\hline & COELOMYCETES & & & \\
\hline 98 & Bartalinia robillardoides & Sporadic & Sporadic & Sporadic \\
\hline 99 & Colletotrichum dematium & & Sporadic & Sporadic \\
\hline 100 & Lasiodiplodia theobromae & Sporadic & Sporadic & Sporadic \\
\hline 101 & Pestalotiopsis guepinii & Sporadic & Sporadic & Sporadic \\
\hline 102 & Phoma betae & Sporadic & Sporadic & \\
\hline 103 & P. capitulum & & Sporadic & \\
\hline 104 & P. exigua & & Sporadic & Sporadic \\
\hline 105 & P. lingam & Sporadic & Sporadic & Sporadic \\
\hline 106 & P. palmicola & & & Sporadic \\
\hline 107 & Phomopsis eugeniae & & Sporadic & \\
\hline
\end{tabular}




\section{Species estimation through extrapolation}

Extrapolation method was used to estimate the total number of species from empirical samples that make up the community, since complete inventories are practically impossible. The most widely used approach for estimating species richness is based on extrapolating from a known species - accumulation curve. This is obtained by plotting the number of species discovered, S (n), within a plot, as a function of the effort expended (n) to find them. In this study, effort is the number of times samples were taken during the 3-year period of study. Following Colwell (2000), the asymptote of the species - accumulation curve, $\mathrm{S}_{\max }$, and a second parameter, $\mathrm{B}$ (number of season surveyed when species richness $=1 / 2$ $\mathrm{S}_{\max }$ ), were estimated using a transformation known as the Eadie-Hofstee equation, which assumes that $S(n)$ is a function of $S(n) / n$, the ratio of species to individuals in the sample. Based on this approach, Michaelis-Menten model and Coleman curve were fitted to the sampling data after randomizing them for 50 times. All these analyses were carried out using the EstimatesS-Win software Version 7.5.2 of Colwell (2000). Several estimators of diversity namely Chao 1 and Chao 2 and ACE, ICE and Jacknife 1 were calculated.

\section{Relationship between relative abundance and species rank}

The total abundance of the different species of fungi observed during the 3-year period was converted into a percentage and plotted against their ranks from the most abundant to least abundant species using PASTA software under the log series model.

In order to present the log normal model the data was rearranged by plotting the frequency of species (the ordinate) against the logarithm of abundance. The logarithms to the base 2 were used as per the conventional procedure in ecological studies so that each class or octave represents a doubling of the previous abundance class.

\section{Community ordination technique}

Principal Components Analysis was computed using the software Paleontological Statistics (Past) version 1.92 with the aim to summarize the relationship between the samples. Sampling units (sites) were arranged in relation to multi coordinate axes such that their relative positions to the axes and to each other provided maximum information about their ecological similarities. The data on the species abundance was used to calculate the Eigen value based on which co-ordinate axes were represented so as to produce information on the similarity of the habitat types. To test for linearity, the data was further subjected to detrended correspondence analysis and the values of the first three axis obtained was used to plot the graph.

\section{Results}

\section{Composition of mycoflora of the three litter layers}

A total of 107 species belonging to 54 genera were isolated from the litter samples. These were made up of 7 species of Zygomycota, 4 species of Ascomycetes 86 species of hyphomycetes and 10 species of coelomycetes. The number of taxa recorded per sampling was higher in F1 layer (23-32) than F2 (14-22) or L (17-25) layers (Table -1). Seven species of Zygomycota were recorded in the F1 layer and 5 species in both the F2 and F3 layers. For Ascomycota, four species were recorded in F1 layer and two each in F2 and L layers. Seventy seven species of anamorphic fungi were recorded in the F1 layer, 61 species in the L layer and 54 species in the F2 layer.

Five species of Zygomycota viz. Absidia corymbifera, Cunninghamella echinulata, Mucor racemousus, Rhizopus stolonifer and Syncephalastrum racemosum were isolated from all three layers of litter. In addition, Cunninghamella elegans and Helicostylum piriforme were isolated from F1 litter only. In the case of Ascomycetes, two species were isolated only from L and F2 litter and four species from F1 litter. Similarly, more hyphomycetes were isolated from $\mathrm{F} 1$ litter followed by F2 and L litter. For coelomycetes, most species were isolated from F2 litter followed by F1 and L litter. Forty one species were present in all three layers, 13 species were present only in $\mathrm{L}$ and $\mathrm{F} 1$ layers, 8 species were present in both F1 and F2 layers and 7 species were 


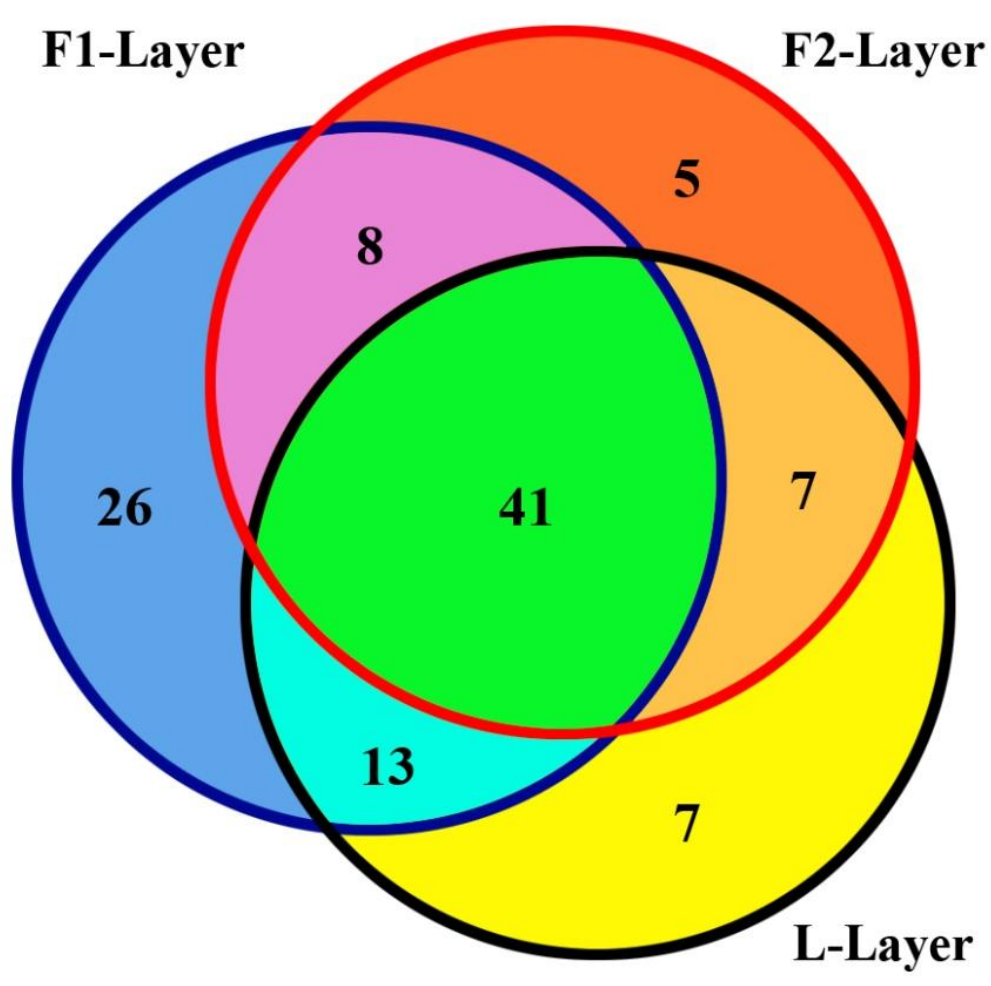

Fig. 1 - Composition of mycoflora among the three litter layers in the Guindy Reserve Forest Number represents total number of species encountered

common to $\mathrm{L}$ and $\mathrm{F} 2$ layers. Twenty six species were specific to F1 layer; 7 and 5 species were specific to L and F2 layers, respectively. (Fig $1)$.

Although many species were recorded in all three layers, their periodicity of occurrence was not the same (Table 1). Aspergillus niger was the only species "most common" in all three layers of the litter. Aspergillus flavus and Penicillium citrinum were "most common" in L and Fl litter but had only the "occasional" and "common" status in the F2 litter. Mucor racemosus and Aspergillus ochraceus were most common in F1 litter but "common" and "occasional" in L and F2 litter, respectively. Aspergillus fumigatus was most common in F1 and F2 litter but "occasional" in the L litter sample.

\section{Species diversity}

Shannon index $\mathrm{H}$ is a diversity index taking into account the number of individuals as well as number of taxa. It varies from 0 for communities with only single taxa to high values for communities with more taxa each with few individuals. The F1 layer had the maximum value of $\mathrm{H}$. This estimator is biased because the total number of species in the community will be greater than the number of species observed in the sample. However if ' $n$ ' is large, this bias will be small. Simpson diversity index $\lambda$ gives the probability that two individuals drawn at random from a population belong to the same species that the diversity of the community is low. Simpson mean $\lambda$ values were higher for the F1 Layer the than L and F2 layer. Fisher's alpha is a useful index for log series models of distribution and the present data falls in this category. The diversity as indicated by Fishers alpha was highest for the F1 layer (Table 2).

\section{Species richness}

The total species richness $S_{\max }$, which is a straight forward measure of species diversity, is given in Table 2. The maximum number of species was recorded in the F1 layer followed by the L layer and the lowest number of species was recorded in the F2 layer. A similar trend was observed for the data on the total number 
Table 2 Diversity indices computed for the fungal species complex at different layers of the forest litter.

\begin{tabular}{clrrr}
\hline S.No & Diversity Indices & L-Layer & F1-Layer & F2-Layer \\
\hline 1 & $\left(\mathrm{~S}_{\text {max }}\right)$ Total Species & 69 & 89 & 62 \\
2 & No. of Colony Forming Unit & 3590 & 4418 & 2909 \\
3 & Dominance_D & 0.03625 & 0.03279 & 0.0464 \\
4 & Berger-Parker & 0.139 & 0.1213 & 0.1653 \\
5 & Margalef R1 & 8.307 & 10.48 & 7.648 \\
6 & Menhinick R2 & 1.152 & 1.339 & 1.15 \\
7 & Evenness_e^H/S & 0.6799 & 0.5989 & 0.6436 \\
8 & Equitability_J & 0.9089 & 0.8858 & 0.8932 \\
9 & Simpson_1-D & 0.9637 & 0.9672 & 0.9536 \\
10 & Shannon_H & 3.848 & 3.976 & 3.686 \\
11 & Simpson mean $\lambda$ & 27.43 & 30.39 & 20.97 \\
12 & Fisher_alpha & 12.12 & 15.79 & 11.13 \\
\hline
\end{tabular}

of (colony forming unit) individuals wherein significantly fewer individuals were recorded in the deeper litter layer (F2 layer). Dominance value ranges from 0 when all taxa are equally present to 1 when one taxon dominates the community completely. The values observed here show a tendency to move towards zero. The Berger Parker dominance index expresses the proportion of the total share that is due to the dominant species. This value was also low for all three layers. Since the F2 layer had fewer species, the Berger-Parker dominance index was higher in the F2 layer than the L and F1 layer.

Since $S_{\max }$ is dependent on the sample size it is limited as a comparative index. Hence two well known indices to measure species richness that are independent of sample size namely Margalef and Menhinick were computed. The values of both these indices were higher in the F1 layer than the L and F2 layers. However, in order to accept these indices according to their face value, it is assumed that a functional relationship exists between the total number of species and total number of individuals observed in the community.

\section{Species evenness}

In analyzing species diversity it is important to also evaluate the equitability or evenness, which indicates the pattern of distribution of individuals between the species.
Evenness refers to how the species abundances are distributed among the species. When all species in a sample are equally abundant, the evenness index would have a maximum value of one and decrease towards zero as the relative abundances of the species moves away from evenness. Evenness values calculated hovered around 0.6 indicating a tilt towards even distribution of the species. A similar trend was observed for the Equitability J values. Simpson index (1-D) measures evenness of the community from zero to one. The value observed here approximated towards one (Table 2).

\section{Seasonal changes in the fungal species composition}

Monthly data on the number of species of fungi inhabiting the forest litter sample was grouped into four periods representing four seasons namely (Fig. 2). Throughout the period of study, the F1 Layer of the forest litter was the most species rich followed by the L layer and F2 layer. The trend indicates that the habitat was highest in fungal species during the NE Monsoon (Sep-Nov). A significant positive correlation was recorded between the fungal species of the three layers and the mean monthly rainfall. $\mathrm{RH}$ also appeared to have an influence on the number of fungal species especially that of the F1 layer, while no correlation was observed with temperature (Table 3). 


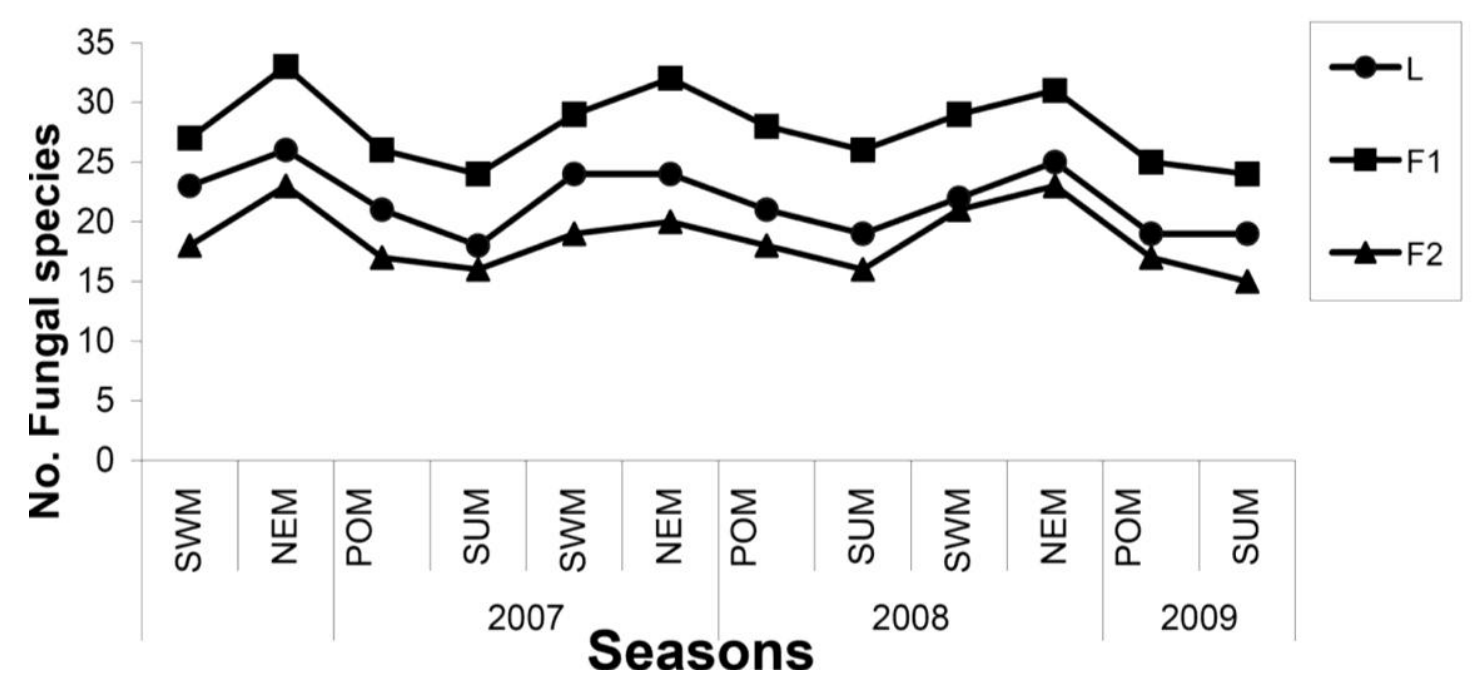

SWM - Southwest monsoon,

NEM -Northeast monsoon,

POM - Post monsoon

SUM - Summer

Fig. 2 - Comparison of number of species recorded in different seasons in the three layers of the forest litter.

\section{Extrapolation of forest litter fungal species diversity}

A few species of fungi are represented by large number of colony forming units and a large number of species by few colony forming units. These relative abundances represent the basic pattern of niche utilization in the community. The characteristic distribution of the various fungal species forming the community becomes evident when relative abundance of each species in the community is plotted in the order of its rank from the most abundant to the least abundant (Fig. 3). This clearly indicates a log normal pattern of distribution pointing towards interplay of many independent factors governing the relative abundance of the species.

\section{Sample rarefaction and non-parametric estimators}

The species (Sample rarefaction) accumulation curve obtained by plotting the cumulative number of species collected against the sampling effort (months) is provided (Fig. 4). In all three layers, the curve assumed asymptote at 12 sampling efforts. The order in which samples are taken alters the shape of the curve. The data basically being a time series one indicate more species of fungi were collected during September to November months which coincided with the rainy season (Fig. 2). Therefore, to eliminate the influence caused by temporal variation, the sample order was randomized 100 times. Extrapolation to estimate the total species complement, $S_{\max }$ is only possible if the species accumulation curve is derived from a reasonably homogenous community. Therefore, heterogencity was tested by rarefaction approach which generates the curve for samples by selection without replacement. If the expected curve rises more steeply from the origin, community is heterogeneous. The curve in this study arose slowly and reached asymptote indicating that the sampling effort was sufficient to predict the species richness. Several non-parametric estimators were calculated for extrapolating the species accumulation curve (Table 4). Values of the abundance based coverage estimator (ACE) of equaled the observed values of the total species fungi in each of the three layers of the litter. Similarly, the incidence based coverage estimator (ICE) also approximated the observed total number of species. Value of Chao 1, Chao 2 and Jack 1 also added support to the observed values of total species recorded in each layer of the litter. 
Table 3 Correlation coefficient computed between the number of fungal species and the prevailing weather parameters.

\begin{tabular}{|l|c|c|c|}
\hline \multicolumn{1}{|c|}{ Litter layer } & $\begin{array}{c}\text { Average Temperature } \\
\left({ }^{\circ} \mathbf{C}\right)\end{array}$ & $\begin{array}{c}\text { Monthly mean Relative } \\
\text { Humidity }\end{array}$ & $\begin{array}{c}\text { Mean monthly Rainfall } \\
(\mathbf{m m})\end{array}$ \\
\hline L-Layer & -0.105 & $0.575^{*}$ & $0.882^{* *}$ \\
\hline F1-Layer & -0.226 & $0.711^{* *}$ & $0.918^{* *}$ \\
\hline F2-Layer & -0.21 & $0.672^{*}$ & $0.879^{* *}$ \\
\hline
\end{tabular}

*Significant at $\mathrm{P}=0.05$, ** Significant at $\mathrm{P}=0.01$

\section{Change in diversity along the litter gradient ( $\beta$ diversity)}

The changes in species diversity along a transect running through the layers of the forest litter was computed by using data on the total number of individuals of each species recorded during the 12 sampling periods (Table 5).

$\beta$-Diversity measures two attributes namely the number of distinct habitats within the region and the replacement of species by another between disjoint parts of the same habitat. The most effective approach used to compare samples along a gradient is the similarity indices. The best index for presenceabsence data is the Jaccard and for quantitative data is the Morista-Horn.

Values of the Jaccard classic as well as the Sorensen classic indicate that the F1 and F2 layers (samples 2 and 3) were more closely similar than either L and F2 (samples 1 and 3). The Morisita-Horn and Bray-Curtis indices based on quantitative data also indicate similar results.

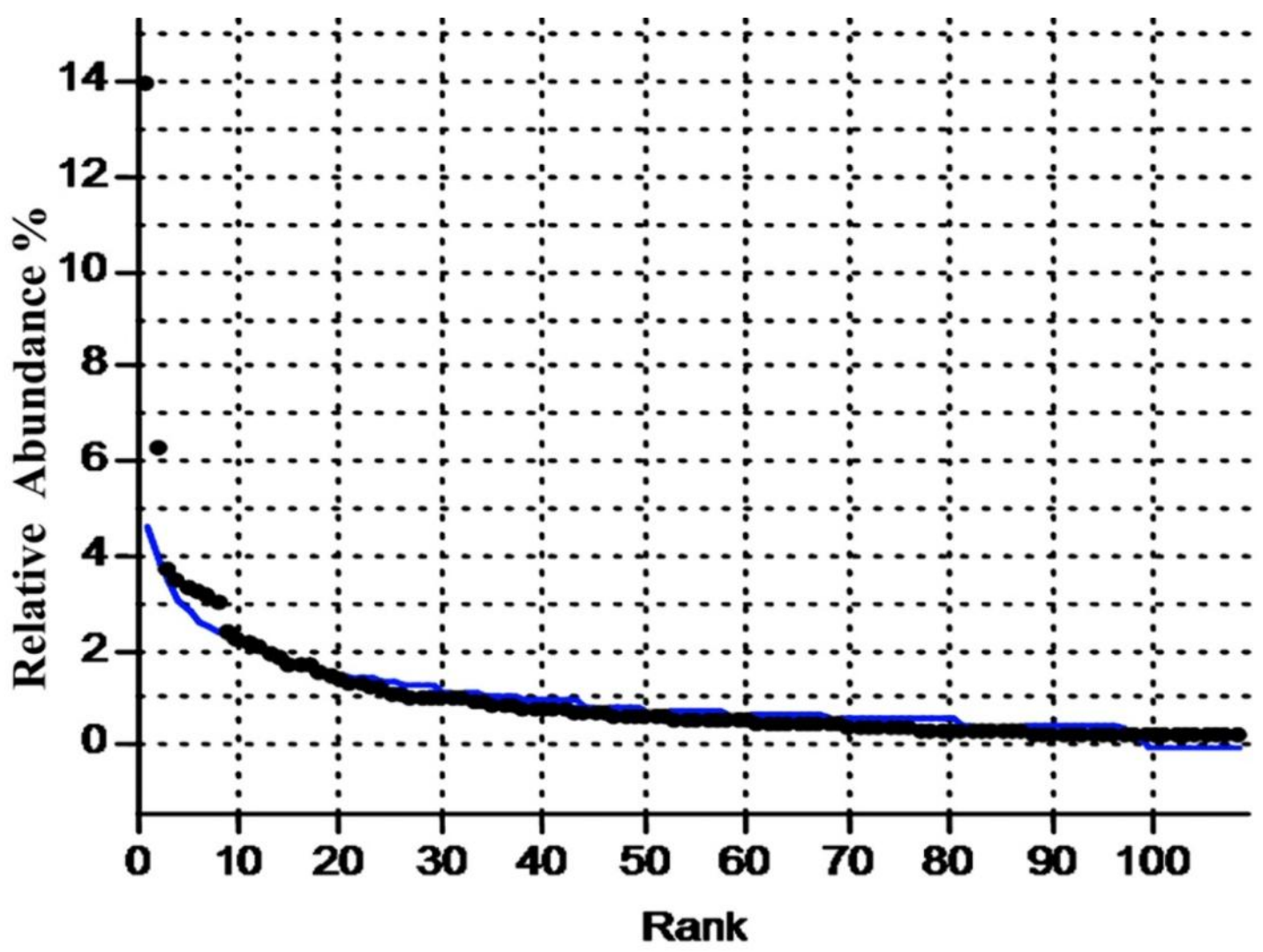

Fig. 3 - Relationship between relative abundance of fungal species and their rank in the forest litter community. 
Table 4 Non parametric estimators of the species accumulation curve.

\begin{tabular}{|l|r|r|r|r|r|r|r|r|}
\hline \multicolumn{1}{|c|}{ Layers } & \multicolumn{1}{c|}{$\begin{array}{c}\text { ACE } \\
\text { Mean }\end{array}$} & \multicolumn{1}{c|}{$\begin{array}{c}\text { ICE } \\
\text { Mean }\end{array}$} & $\begin{array}{l}\text { Chao 1 } \\
\text { Mean }\end{array}$ & $\begin{array}{c}\text { Chao 2 } \\
\text { Mean }\end{array}$ & $\begin{array}{l}\text { Jack 1 } \\
\text { Mean }\end{array}$ & $\begin{array}{c}\text { Jack 1 SD } \\
\text { (analytical) }\end{array}$ & $\begin{array}{c}\text { Bootstrap } \\
\text { Mean }\end{array}$ & \multicolumn{1}{c|}{$\begin{array}{c}\text { MM } \\
\text { Means (1 run) }\end{array}$} \\
\hline L-Layer & 69 & 71.85 & 69 & 69.63 & 74.5 & 2.53 & 74.06 & 88.84 \\
\hline F1-Layer & 88 & 89.54 & 88 & 88.07 & 90.75 & 1.44 & 94.16 & 116.05 \\
\hline F2-Layer & 61 & 61 & 61 & 61 & 61 & 0 & 64.49 & 83.53 \\
\hline
\end{tabular}

$\mathrm{ACE}=$ Abundance based coverage Estimator, $\mathrm{MM}$ mean $=$ Michaelis Menton mean $\mathrm{ICE}=$ Incidence based Coverage

Estimator

\section{Community classification and ordination}

Community classification plays a fundamental role in understanding the natural system that has led to the observed grouping of the species. Each species in the group has a number of common characteristics that set them apart from each other group. An attempt has been made here to classify the species in the community using a polythetic, hierarchical, agglomerative techniques namely cluster analysis.

Fig. 5 classifies the litter fungal community into clusters based on the Jaccard similarity indices. The L and F2 layers of litter formed a cluster based on a $60 \%$ similarity resembled one another and formed a group that was distinct from Curvularia oryzae. The remaining fungal species formed two distinct between them and was separated from the F1 layers by a difference of about $8 \%$ only.

The data recorded on the abundance of individual species of fungi over the 12 season of sampling was used to group the various species reflecting their overall resemblance to one another. Dendrograms of the clustering of the species using Euclidean distance is provided (Fig. 6). Aspergillus niger formed a separate group in the community. Simlarly the nonsporulating fungi group also differed from the other species of fungi. Aspergillus ochraceus, A. flavus, A. fumigatus, Mucor racemosus, Rhizopus stolonifer and Penicillium citrinium groups. Therefore, arbitrarily six distinct groups are identifiable based on the abundance of the fungal species.
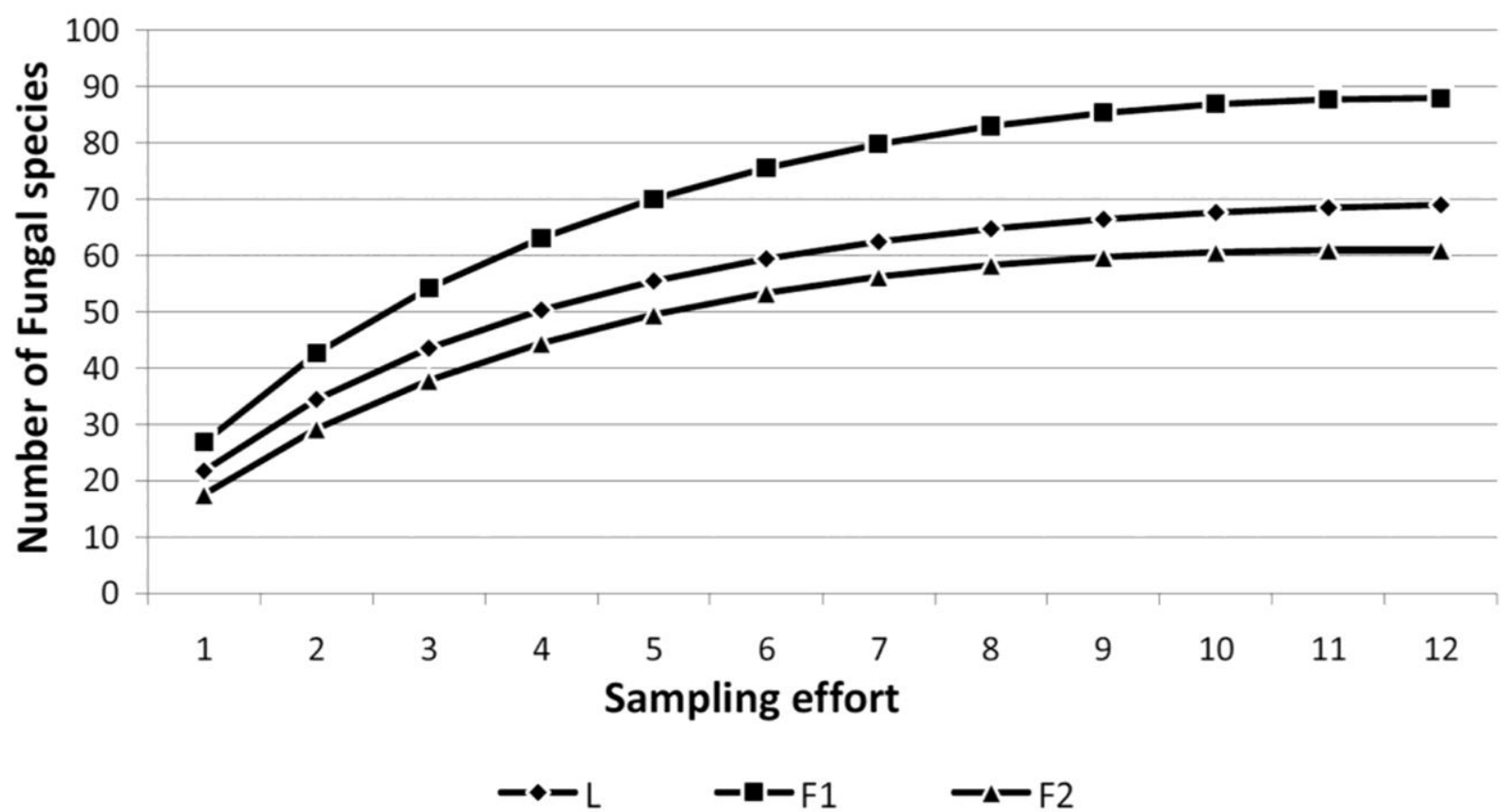

Fig. 4 - Species accumulation curve 
Table 5 Comparison for fungal species diversity among the three layers of the forest litter.

\begin{tabular}{|l|r|r|r|}
\hline First Sample & 1 & 1 & 2 \\
\hline Second Sample & 2 & 3 & 3 \\
\hline Sobs First Sample & 69 & 69 & 89 \\
\hline Sobs Second Sample & 89.00 & 62.00 & 62.00 \\
\hline Shared Species Observed & 55 & 49 & 50 \\
\hline ACE First Sample & 69 & 69 & 89 \\
\hline ACE Second Sample & 89 & 62 & 62 \\
\hline Jaccard Classic & 0.533 & 0.597 & 0.495 \\
\hline Sorensen Classic & 0.699 & 0.748 & 0.662 \\
\hline Chao-Jaccard-Raw Abundance-based & 0.759 & 0.758 & 0.747 \\
\hline Chao-Jaccard-Est Abundance-based & 0.759 & 0.758 & 0.747 \\
\hline Chao-Sorensen-Raw Abundance-based & 0.863 & 0.862 & 0.855 \\
\hline Chao-Sorensen-Est Abundance-based & 0.863 & 0.862 & 0.855 \\
\hline Chao-Sorensen Est Abundance- based & 0.863 & 0.862 & 0.855 \\
\hline Morisita-Horn & 0.94 & 0.932 & 0.923 \\
\hline Bray-Curtis & 0.734 & 0.737 & 0.683 \\
\hline
\end{tabular}

Sample 1=L Layer, Sample 2=F1 Layer, Sample 3= F2 Layer

\section{Principal component ordination}

A community ordination technique was performed in which the seasons of sampling are arranged in relation to the coordinate axes such that their relative position to the axes and to each other provides maximum information F1 layer is provided (Fig.7).
PCA helps in breaking down or partitioning a resemblance matrix into a set of perpendicular axes or component. Each PCA axis or component correspond to an eigenvalue of the matrix. The eigenvalue is the variance accounted for by the axes. The eigenvalues are extracted in the descending order of magnitude

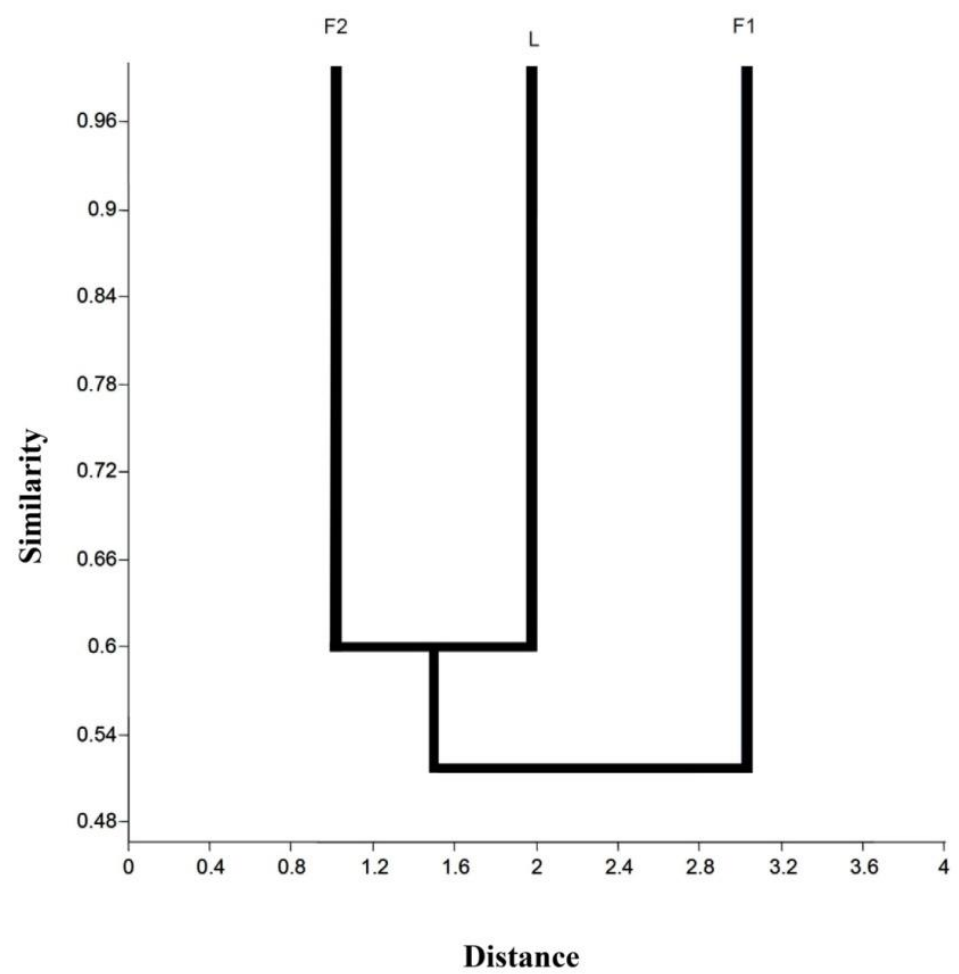

Fig. 5 - Dendrogram for the cluster analysis classifying the three layers of the forest litter based on the Jaccard index of similarity. 
Table 6 Principal components analysis for four seasons based on the abundance of 23 fungal species of the F1 Layer: Coordinate of the first four axis.

\begin{tabular}{|l|r|r|r|r|}
\hline \multicolumn{1}{|c|}{ Seasons } & \multicolumn{1}{c|}{ Axis 1 } & \multicolumn{1}{c|}{ Axis 2 } & \multicolumn{1}{c|}{ Axis 3 } & \multicolumn{1}{c|}{ Axis 4 } \\
\hline SWM & -0.32 & 0.10 & -1.46 & -2.73 \\
\hline NEM & -1.28 & -0.11 & 0.78 & -2.17 \\
\hline PM & 0.75 & 1.23 & 0.43 & 1.09 \\
\hline SUM & 0.85 & -1.21 & 0.25 & 4.20 \\
\hline
\end{tabular}

such that the correspondingly PCA components represent correspondingly greater to lesser amount of variation in the matrix. Hence, the first few PCA axes upon which species (season) is positioned will represent the largest percentage of the total variation. Values of the first 4 components are given (Table 6).The PC ordination plotting Component 1 vs Component 2 indicate that the data of the fungal species abundance during the North East monsoon and
South West monsoon were positioned towards the - ve side of the axis while the post monsoon and summer were towards the +ve side. Also the greatest variation was accounted to be due to the South West monsoon (Fig.7).

The component 3 would account for lesser variation in the matrix than 1 and 2 . Plotting of component 3 vs component 1, also indicates the data during the North East monsoon and South West monsoon to fall on

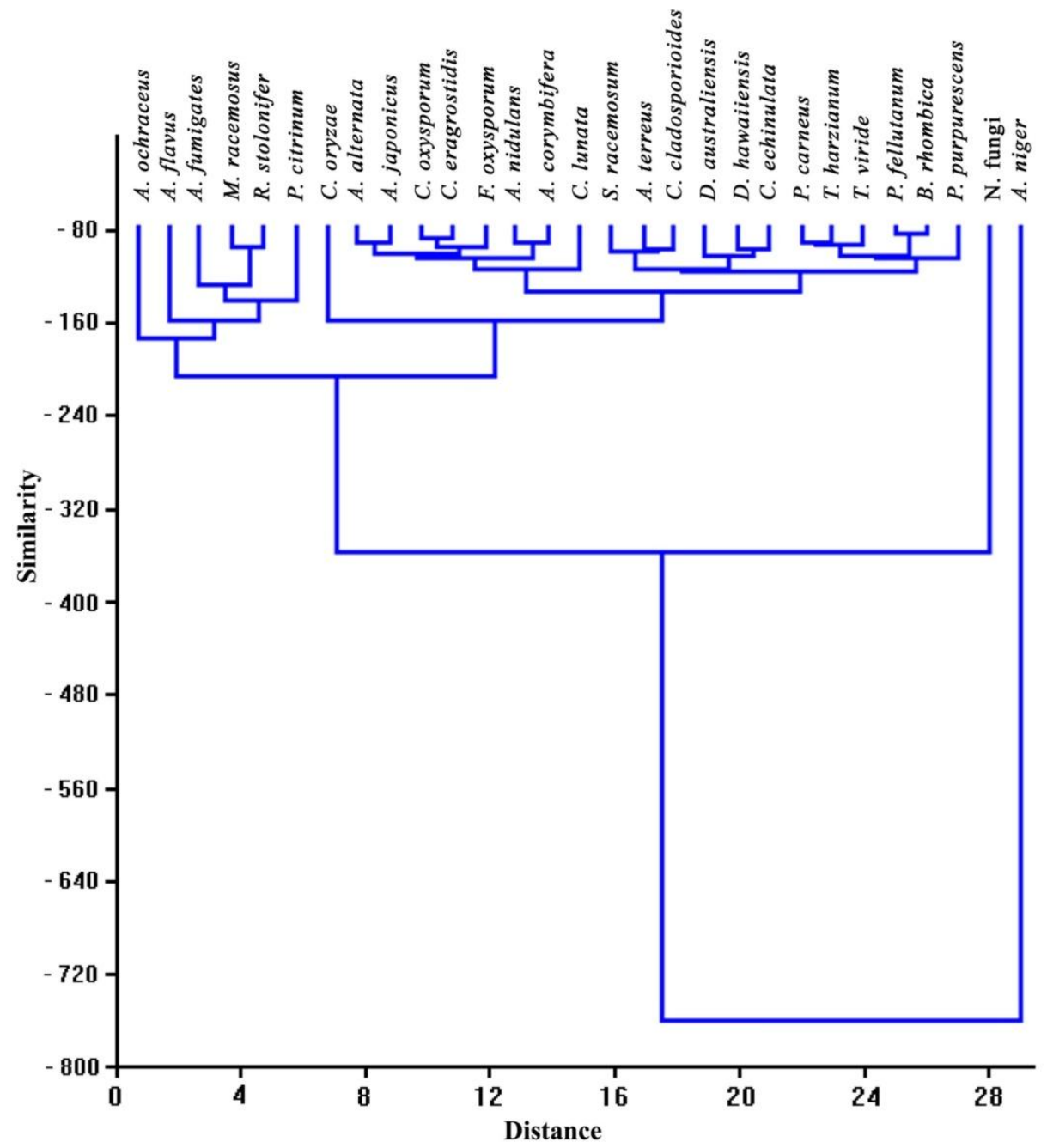

Fig. 6 - Dendrogarm clustering the 29 abundant fungal species of the forest litter using euclidean distance. 
Table 7 Detrended correspondence analysis value: Coordinates of the first three axis.

\begin{tabular}{|l|c|c|c|}
\hline Seasons & Axis1 & \multicolumn{1}{l|}{ Axis2 } & Axis3 \\
\hline SWM & 0.14 & 0.15 & 0.15 \\
\hline NEM & 0 & 0 & 0 \\
\hline PM & 0.39 & 0.37 & 0.39 \\
\hline SUM & 0.6 & 0.32 & 0.35 \\
\hline
\end{tabular}

the left hand side while the post monsoon and summer on the right hand side. The biplot depicting the positioning of the various species about the centre is also presented. Fig. 7 depicts the plotting of component 3 with the component 2. The 23 species of fungi appears to be dispersed around the central axis indicating no specific orientation.

\section{Detrended correspondence analysis}

In studies where the sampling units occur at wide environmental gradients, the species abundance patterns are typically nonlinear and this can cause difficulties in interpretation. To overcome this, detrended correspondence analysis was attempted. The values of the first three axis obtained by computing the detrended correspondence analysis is provided to in (Table 7). Detrended correspondence analysis plotting axis 1 and axis 2 (Fig. 8) and axis 2 with axis 3 indicate a linear arrangement of the four seasons. Species abundance contributing to the data of the North East monsoon and South West monsoon was closer to the central axis than the post monsoon and summer indicating the ecological importance of environment on the species distribution.

\section{Discussion}

Investigations of tropical forest soil fungi have focused largely on those associated with leaf litter (Paulus et al. 2006, Duong et al. 2008) and most assemblages of micro fungi sporulating on decomposing leaves have been identified following laboratory incubation (Parungao et al. 2002, Rambelli et al. 2004, Thongkantha et al. 2008). However, investigation of total soil fungal assemblages in tropical forests have been more limited and have relied on dilution plating approaches (Mohanty \& Panda 1994, Persiani et al. 1998).
There has been no specific study on the alkalotorent species inhabiting the leaf litter and in this sense the present study appears unique. A total of 107 species were identified from this forest ecosystem and these species were capable of growing in alkaline $\mathrm{pH}$. There was a distinct pattern of occurrence of fungal species in the different layers of the litter, indicating the specific functional role they play in the process of litter degradation. The exclusive occurrence of fungal species in particular layers was also reported by Watson et al. (1974) for hard wood and pine litter. That the fungal diversity varies depending on the needle type has been emphasized by Tokumasu et al. (1997) in studies on microfungal communities in pine leaf litter in Thailand. Such selective distribution of fungal species at different strata of the habitat might relate to the specific functional role they play in the community and also signifies the specific niche requirements of the species.

\section{Periodicity of occurrence and percentage frequency}

In the present study a somewhat arbitrary grouping of fungi has been made on the basis of their periodicity of occurrence i.e., the number of samplings in which each fungus was found to occur as against the total number of samplings. Four groups were recognized; species showing $76-100 \%$ periodicity of occurrence were regarded as "most common", $51-75 \%$ as "common"; $26-50 \%$ as "occasional" $1-25 \%$ "sporadic". Not that this is a perfect classification but yet it was felt that this would give some idea on the periodicity of occurrence and facilitate description. Although several fungal species were common components of the mycoflora of all the three layers of the Guindy Forest litter, it was noticed that each layer had its own characteristic flora with regards to their periodicity of occurrence. Aspergillus niger 

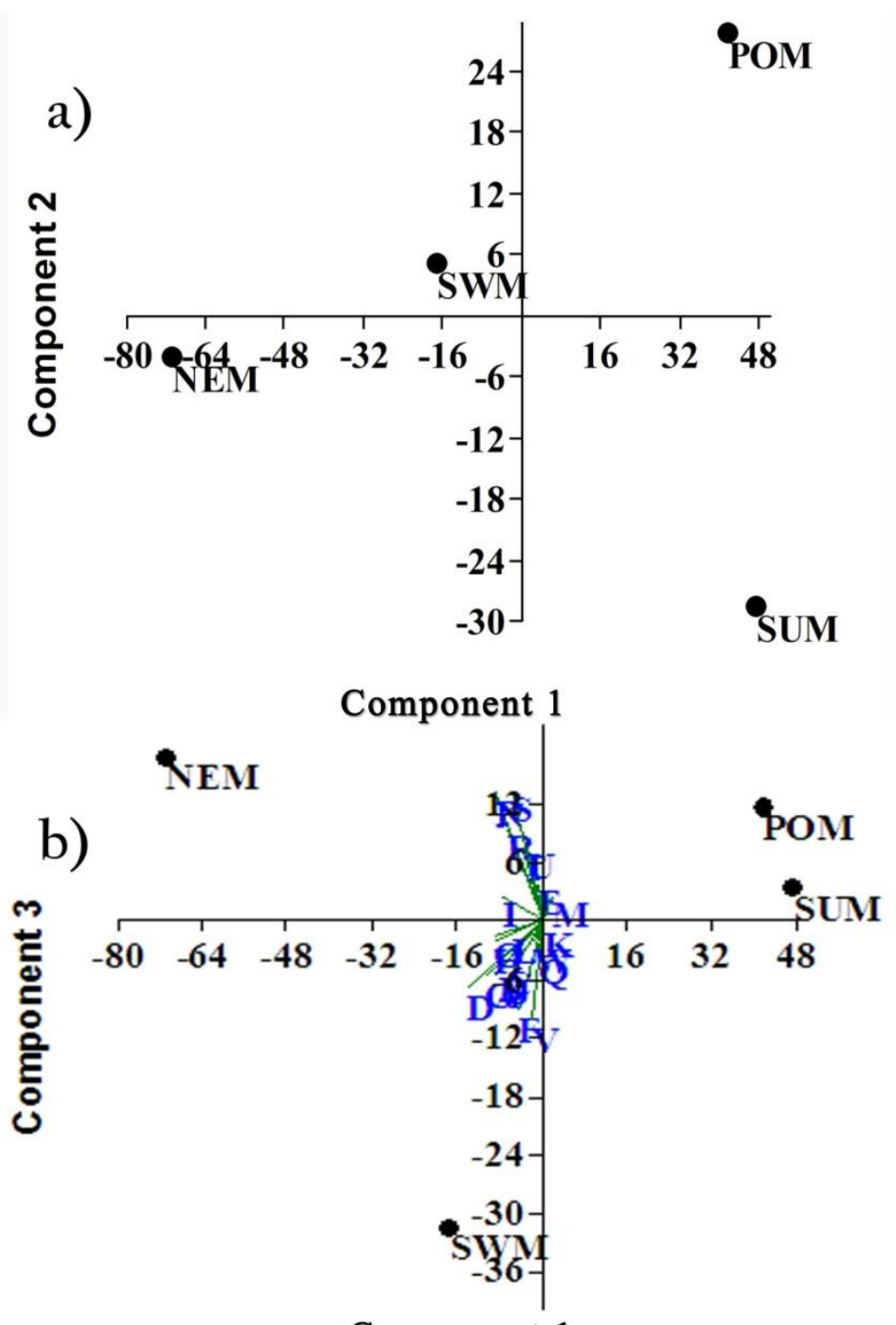

Component 1

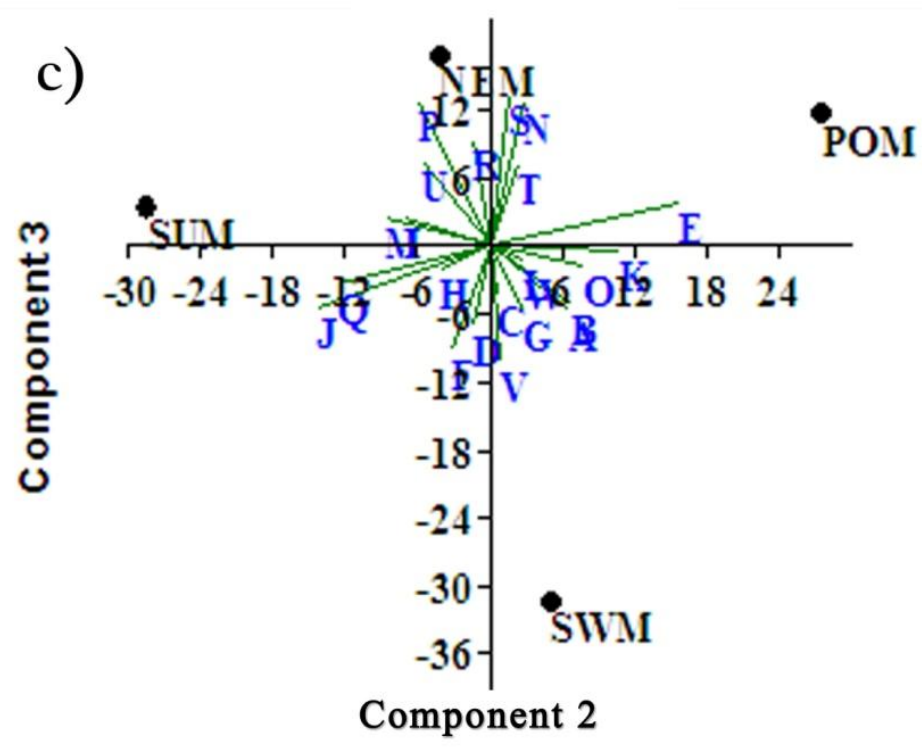

SWM - Southwest monsoon

NEM -Northeast monsoon

POM - Post monsoon

SUM - Summer

Fig. 7 - Principal component ordination: Position of four seasons based on fungal species abundance a) Principal Component 1 Vs 2 b) Component 1 Vs Component 3 and c) Component 2 Vs Component 3. 
showed the highest average percentage occurrence in all the three layers of litter. Penicillium citrinum was among the 'most common' category in L layer of the litter. Mucor racemosus, A. flavus, A. fumigatus, A. ochraceus, and Pencillium citrinum were 'most common' in the F1 litter. Aspergillus fumigatus was among the 'most common' category in F2 litter. Such difference among different categories of litter were reported by Vittal (1973), Sudha (1978), and Dorai \& Vittal (1988). In general, many fungi appeared sporadically with low frequency. Only a few species were constant throughout the decomposition process. A similar observation was made by Watson et al. (1974) and Heredia (1993).

\section{Seasonal changes in species composition}

The GRF was highest in fungal species during the North East monsoon. In the southern Indian plains, the ideal season for fungal growth has been observed to be the monsoon period (Maria \& Sridhar 2004) which is in agreement with the present study. Zhou \& Hyde (2002) also suggested that seasonality has an effect on fungal composition in the habitat, as more fungi were present during the wet season. They concluded that rainfall positively impacted on fungal occurrence, but temperature and relative humidity appeared to have little influence. Many authors have reported that seasonality affects fungal divestiy. Tokumasu (1998) observed that the temperature at the surface of decaying needle litter of Pinus densiflora was a major factor contributing to seasonal changes in interior fungal communities. Pandey \& Dwivedi (1984) also observed that Colletotrichum gloeosporioides, Fusarium oxysporum, and F. psidii on the leaves of Psidium guajava were recorded more frequently in the rainy season. Similarly, in the present study, Periconia clitoriae, Lasiodiplodia theobromae, Pestalotiopsis guipenii, and Beltraniopsis asperisetifer were isolated only during the North East monsoon. Leung (1998) also suggested that seasonal factors, especially air temperature and rainfall affected the development of the fungal communities on bamboo litter. Rainfall is therefore, an important factor that has the effect of increasing fungal diversity. A significant positive correlation was recorded between the fungal species of the three layers of the GRF litter and the mean monthly rainfall. Relative humidity (RH) also appeared to have an influence on the number of fungal species especially that of the F1 layer, while no correlation was observed with temperature.

The log normal distribution of fungal community observed in the present study indicates that the niche of a species is dependent on a multitude of different factors and that the amount of resources used by each species is normally distributed. This distribution pattern also indicates that many independent factors govern the relative abundances of the species and the fungal community at GRF habitat appears to be a heterogeneous assemblage although the samples were drawn from a homogenous habitat. Detrended correspondence analysis plotting axis 1 with axis 2 and axis 2 with axis 3 indicate a linear arrangement of the four seasons for the data. Species abundance contributing to the data of the north east monsoon and south west monsoon was closer to the central axis than the post monsoon and summer indicating the ecological importance of environment on the species distribution.

Senthilkumar et al. (1993) reported that Acremonium sp., Alternaria alternata, Aspergillus flavus, A. nidulans, A. niger, A. terrus, Aureobasidium pullulans, Chaetomium lunasporium, Colletotrichum dematium, Curvularia lunata, Drechslera halodes, Emericella nidulans, Fusarium solani, Mucor racemosus Nigrospora sphaerica, Pithomyces chartarum Rhizopus stolonifer, Trichoderma koningii, and $T$. viride, were major mycoflora associated with litter degradation in tropical grasslands of south India. Similar species were also encountered in litter samples of GRF. Some interesting conclusions emerged from results of this investigation. Firstly, even though the freshly fallen leaves are rich in nutrients, they are in less utilizable form; the fungal communities require a helping hand from shredders (snails and other macro-invertebrates). Whereas, the middle layer (F1 layer) is usually rich in coarse particulate organic matter (Garrett 1963, Kirk et al. 1980) which can be solely and easily handled by the fungal community. Hence, the explosion of diversity was observed in F1 layer. 

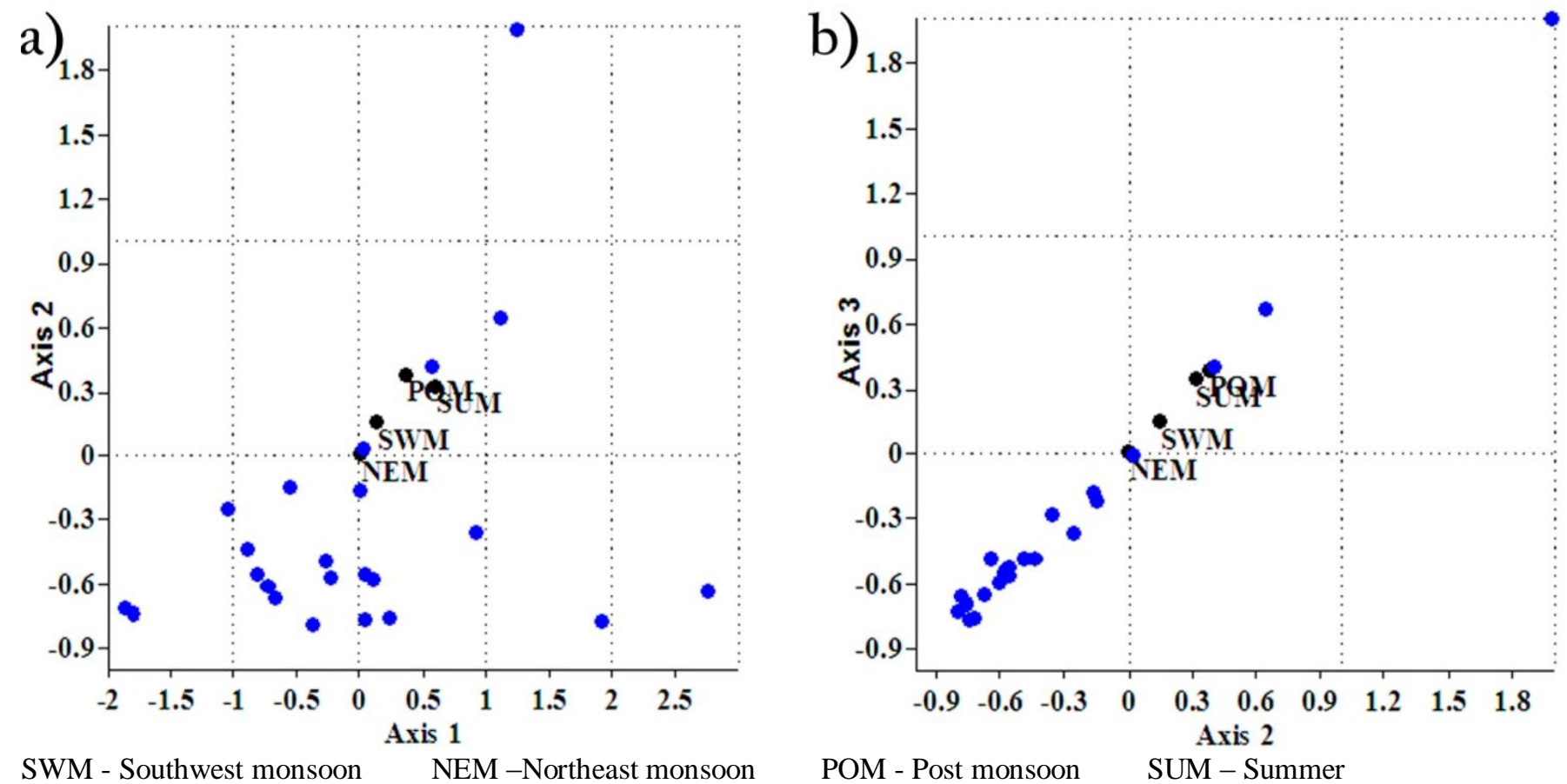

Fig. 8 - Detrended correspondence analysis for four seasons based on the abundance of 23 fungal species of the F1 Layer a) axis 1 vs axis 2 b) axis 2 vs axis 3 .

Secondly, the specific association of fungal species in different layers is due to their niche specialization. Senthilkumar et al. (1993) reported that most of the fungal flora occurring in the later stages of decomposition (F1 litter layer) were efficient degraders of cellulose and lignin. In the present study more fungal species were recorded in Fl litter layer compared to $\mathrm{L}$ and F2 layer.

During the later stages of decomposition the initial colonizers gradually disappeared and were replaced by new colonizers. This could be due to the availability of different kinds of nutrients from the substrate at various stages of decomposition. This phenomenon probably plays a vital role in specific association of fungal species in different layer in the litter. Few of the fungi occurring in surface litter are well known plant pathogens, an observation also reported by Stakman \& Harrar (1957). This supports the hypothesis that fungi capable of infecting living leaf could be the initiators of litter degradation.

\section{References}

Colwell RK 2000 - EstimateS: Statistical estimation of species richness and shared species from samples. Version 6B1a. User's guide and applications published at http://viceroy.eeb.uconn.edu/estimates.

Cooke RC, Rayner ADM. 1984 - Ecology of saprotrophic fungi. London, UK, Longman. $415 \mathrm{p}$.

Dorai M, Vittal BPR. 1988 - Cercosperma longispora sp. nov. from India. Transactions of the British Mycological Society 91, 521-523.

Duong LM, McKenzie EHC, Lumyong S, Hyde KD. 2008 - Fungal succession on senescent leaves of Castanopsis diversifolia in Doi Suthep-Pui National Park, Thailand. Fungal Diversity 30, 23-36.

Garrett SD. 1963 - A comparison of cellulosedecomposing ability in five fungi causing cereal foot rots. Transactions of the British Mycological Society 46, 572-576.

Heredia B. 1993 - The status and conservation of Aquatic Warbler. Birding World 6, 294-295.

Horikoshi K. 1999 - Alkaliphiles: some applications of their products for biotechnology. Microbiology and Mole- 
cular Biology Reviews 63, 735-750.

Horikoshi K, Akiba T. 1982 - In Alkalophilic Microorganisms. A New Microbial World, Tokyo: Japan Scientific Societies Press \& Springer 75-77.

Jones BE, Grant WD, Collins ND, Mwatha WE. 1994 - Alkaliphiles: diversity and identification. In: Priest FG, Ramos AG, Tindall B. (eds.). Bacterial Diversity, and Systematics, New York, Plenum Press. 195-230

Kirk TK, Higuchi T, Chang HM. 1980 - Lignin biodegradation: microbiology, chemistry, and potential applications, Vol. 1, CRC Press.

Kjoller A, Struwe S. 1982 - Microfungi in ecosystems: fungal occurrence and activity in litter and soil. Oikos 39, 389422.

Leung SS 1998 - A Study of Saprophytic Fungi Associated with Bamboo Culms in Terrestrial, Freshwater and Marine Habitats. Ph.D. thesis, Department of Biology and Chemistry, The City University of Hong Kong, Hong Kong SAR, P.R. China.

Manoharachary C, Sridhar K, Singh R, Adholeya L, Suryanarayanan TS, Rawat S, Johri BN. 2005 - Fungal biodiversity: distribution, conservation and prospecting of fungi from India. Current Science 89, 58-71.

Maria GL, Sridhar KR, 2004 - Fungal colonization of immersed wood in mangroves of the southwest coast of India. Canadian Journal of Botany 82, 1409-1418.

Mohanty RB, Panda T. 1994 - Ecological studies of the soil microfungi in a tropical forest of south Orissa in relation to deforestation and cultivation. Journal of Indian Botanical Society 73, 213.

Pandey RR, Dwivedi RS. 1984 - Seasonal incidence of phylloplane mycoflora of guava (Psidium guajava) with reference to fungal pathogens. Acta Botanica Indica 12, 1-18.

Parungao MM, Fryar SC, Hyde KD.2002 Diversity of fungi on rainforest litter in north Queensland, Australia. Biodiversity and Conservation 11, 1185-1194.
Paulus B, Gadek P, Hyde KD. 2006 Successional patterns of microfungi in fallen leaves of Ficus pleurocarpa (Moraceae) in an Australian tropical rain forest. Biotropica 38, 42-51.

Persiani AG, Maggi MA, Pineda FDC. 1988 Diversity and variability in soil fungi from a distributed tropical rain forest. Mycologia 90, 206-214

Rambelli A, Mulas B, Pasqualetti M. 2004 Comparative studies on microfungi in tropical ecosystems in Ivory Coast forest litter: behaviour on different substrata. Mycological Research 108, 325-336.

Senthilkumar K, Udaiyan K, Manian S. (1993). Successional pattern of mycolfora associated with litter degradation in a Cymbopogon caesius-dominated tropical grassland. Tropical Grasslands 27, 121-127

Stakman EC, Harrar JR, 1957 - Priciples of plant pathology. Roland Press, New York, 581.

Sudha K 1978- Study of mycoflora of leaves and litter, Ph.D Thesis, University of Madras.

Swift MJ, Heal OW, Anderson JM. 1979 Decomposition in terrestrial ecosystems. Studies in Ecology, Blackwell Scientific Publications, Oxford. 5, 372.

Thongkantha S, Lumyong S, McKenzie EHC, Hyde KD. 2008 - Fungal saprobes and pathogens occurrence on tissues of Dracaenaloureiri and Pandanus spp. Fungal Diversity 30, 149-169.

Tokumasu S 1998 - Fungal succession on pine needles fallen at different seasons: The succession of interior colonizers. Mycoscience, 39, 409-416.

Tokumasu S, Tubaki K, Manoch L. 1997 Microfungal communities on decaying pine needles in Thailand. In: Janardhanan, K.K. et al., (Eds.), Tropical mycology Oxford and IBH Publishing Company 93-106.

Vittal BPR 1973 - Studies on the mycoflora of leaves and litter. Ph.D. Thesis, University of Madras.

Watson ES, Mcclurkin C, Huneycutt MB. 1974 - Fungal succession on loblolly pine and 
upland hardwood foliage and litter in north Mississippi. Ecology 55, 11281134.

Zhou DQ, Hyde KD. 2002 - Fungal succession on bamboo in Hong Kong. In: Hyde KD, Jones EBG. (eds.). Fungal Succession Fungal Diversity 10, 213227. 